\title{
A study on the effect of P/E and PEG ratios on stock returns: Evidence from Tehran Stock Exchange
}

\section{Seyyed Ali Lajevardi ${ }^{*}$}

Department of Management and Accounting, Kashan Branch, Islamic Azad University, Kashan, Iran

C H R O N C L E A B T R A T

Article history:

Received January 14, 2014

Accepted 10 June 2014

Available online

June 162014

Keywords:

P/E ratio

PEG ratio

Tehran Stock Exchange

\begin{abstract}
This paper studies the effect of the ratios of P/E and PEG on stock returns of the firms accepted on Tehran Stock Exchange. The study uses regression and Pearson Correlation Coefficient based on the performance of 138 firms over the period 2004- 2009 according to the Iranian calendar to investigate the effects of P/E and PEG on stock returns. The study also uses the models originally proposed by Chahin and Choudhry (2010) [Chahin, S., \& Choudhry, T. (2010). Price to earnings, growth radio and value growth based strategies. Social Science Research Network, 19(4).] to discuss the strategies of investing on stocks. The results show that the ratio of $\mathrm{P} / \mathrm{E}$ had more effect on stock returns than the ratio of PEG and stocks returns had a direct relationship with $\mathrm{P} / \mathrm{E}$ and an inverse relationship with PEG. In addition, the returns of growth stock were more than value stock.
\end{abstract}

\section{Introduction}

Investment is one of the most important factors for business development in the present century. Stock Exchange is one of the most important places in this regard, which provides savings for investment for the manufacturing sector and industry. It also helps the equitable distribution of wealth, inflation control, national growth, and finally economic balance of the country through controlling the volume of money and liquidity in the society. Extensive reviews and studies should be accomplished and many items should be taken into account by investors when they wish to invest in common stock. This is because they are converting their most cash assets into common stock. This plays more importance in a stock market that has no returns or its returns is very poor, because the prices of stock market are not close to the real and intrinsic values, unlike the countries that have stock markets with high efficiency and returns. Hence, if investors are informed of capital market and all effective factors in investment, they can make better decisions and it would lead to the boom of capital market. Stock return is one of the factors influencing investors' purchase decisions. Since the

*Corresponding author.

E-mail addresses: a.lajevardi@iaukashan.ac.ir (S. A. Lajevardi) 
analysis of financial ratios is of great importance for realization and prediction of future returns of stock, if we can predict the returns of stock and offer a way to support this prediction, better and more certain conditions will be provided to attract and to encourage investors to invest on stocks. This study aims to explain the effect of the ratios of price per earnings $(\mathrm{P} / \mathrm{E})$ and price/earnings to growth (PEG) on stock returns of the firms accepted in Tehran Stock Exchange.

In the competitive environment of today's capital market, the future belongs to investors who use the best tools for financial analysis and performance evaluation and decision-making. Stock return is reliable and logical way, which investors can use it to compare the alternative and different investments with each other. According to the theory of agency and the desire of investors, the objective of management should be to maximize the wealth of shareholders. This is realized when the decisions of management on investment are taken with financing and optimal sharing of profit. Criteria such as price per share, dividends per share, benefits of precedence, and so on are effective in determination of minimizing the wealth of shareholders. Analysis of financial ratios can be used to get a better understanding and predict the future returns of stock.

There are two major objectives in the theory of capital markets:

A) Providing information that will assist the optimal resource allocation: This means that manufacturers can allocate a certain amount of their capital resources to maximize the returns and gross domestic production (GDP).

B) Providing information that help investors choose the best set of stocks with a low risk and high returns among different sets of stocks in the market and use accounting data to determine their portfolio considering their risk and returns.

In order to achieve the second objective of capital market theory, it is essential to use benchmarks and tools to classify, rate, and determine the returns of stock. Hence, the present study aims to review the ratios of PEG and P/E and the effects of each on stock returns of the firms accepted in Tehran Stock Exchange and tries to answer this question that how the effects of the ratios of PEG and $\mathrm{P} / \mathrm{E}$ on stock returns of the firms accepted in Tehran Stock Exchange is.

\section{Literature review}

The use of financial ratios is one of the most common and most popular methods for the analysis of financial statements. Actually, financial ratios compare the relationship between accounting variables such as sales and profits; sales, assets, and liabilities; and liabilities and the rights of shareholders. In other words, financial ratio is a fraction that its numerator includes two or more financial variables such as assets, liabilities, capital, revenues, costs, profits, etc. and its denominator consists of components such as assets, liabilities, and so on and shows their relationship as weight, rate, percentage, and so on (Nikoomaram et al., 2009).

\subsection{The ratio of $P E G$}

The ratio of PEG was developed to explain the effect of growth rate on the ratio of P/E. PEG Ratio is calculated by the following formula:

$$
P E G=\frac{\text { Price } / \text { Earning Ratio }}{\text { Rateof Growth Earning }}
$$


According to PEG ration, if the price of a share is to be fair, its $\mathrm{P} / \mathrm{E}$ Ratio should be equal with dividend growth rate. If the PEG ratio is equal to one, it indicates that the market has been realistic in pricing stock, considering the growth rate of earnings per share, and has made no mistake. If the PEG ratio is bigger than 1, it indicates that the price of stocks has been overestimated or the market expects that the dividend growth rate be much higher than predicted in future years. If the PEG ratio is less than one, it indicates that the stock have been priced lower than their intrinsic value in the market or the market expects that the firm cannot achieve its expected objectives and dividend. In other words, it can be said that low PEG indicates the ratio of PE to dividend growth rate is low and promises a better future for stock returns. By contrast, high PEG indicates that the ratio of PE to dividend growth rate is high and a low returns is expected for those stock (Easton, 2004).

\subsection{Previous studies on P/E ratio}

Basu (1977) studied price per earnings (P/E) ratio through ranking of shares using $\mathrm{P} / \mathrm{E}$ ratio and compared income from stock group with a high $\mathrm{P} / \mathrm{E}$ and income from stock group with a low $\mathrm{P} / \mathrm{E}$ over the period 1956-1971. The initial data of research were obtained from Cornell University and data associated with investment returns were extracted from the Center for Research in Security Prices. Basu chose 753 firms and primarily calculated the P/E of firms in each year and ranked the firms based on this ratio and categorized them in portfolios $\mathrm{A}, \mathrm{B}, \mathrm{C}, \mathrm{D}$, and $\mathrm{E}$ where $\mathrm{A}$ represents the highest $\mathrm{P} / \mathrm{E}$ ratio and $\mathrm{E}$ represents the lowest one. After one year, the return of each portfolio was calculated and portfolios were rearranged. Systematic risk of portfolios during 168 months were calculated based on their returns using a regression model and then $\beta$ was determined. Finally, in order to consider the risk of portfolio, portfolio returns were modified using the indices of Jensen, Trainer, and Sharp and the modified returns were compared using these three indices. After statistical tests, it was found that after modification of risk, at an error level of $5 \%$, the reformed portfolios with a low $\mathrm{E} / \mathrm{P}$ had a better performance than portfolios with a high $\mathrm{P} / \mathrm{E}$. These relationships were still true after the modifications related to tax. However, the results were not consistent with Capital Asset Pricing Model and the Efficient Market Hypothesis. Basu argued that information on P/E ratio of firms were reflected in stock price as it is expected from a semi-strong efficient market. Goodman and Peavy III (1985) studied P/E ratio by focusing on both total and systematic risk. The results indicated that the stock with a low $\mathrm{P} / \mathrm{E}$ at risk levels had a significant positive extra returns.

Fama and French (1993) conducted a similar study in 1998 on global market over the period 19751995. They compared the returns of value stock and growth stock in 11 countries including the U.S., Japan, France, Germany, Italy, Netherlands, Belgium, Sweden, Australia, Hong Kong, and Singapore. The results of this study in the U.S. showed that value stock of firms with a high book value to market value ratio $(\mathrm{B} / \mathrm{M})$, earnings per share for share prices ratio $(\mathrm{E} / \mathrm{P})$, and cash flow to price ratio $(\mathrm{C} / \mathrm{P})$ created higher returns compared with growth stock of firms with a low $(\mathrm{B} / \mathrm{M}),(\mathrm{E} / \mathrm{P})$, and $(\mathrm{C} / \mathrm{P})$. Information needed for this study were obtained from CRPS and COMPUSTAT for the U.S. stock market and from MSCI for the other 10 countries. Then, these firms were investigated and ranked according to above-mentioned ratios and the ratio of dividends to price per share (D/P). Jahankhani and Parsaian (1997) studied this issue on Tehran Stock Exchange. They divided 67 firms into 4 portfolios according to $\mathrm{P} / \mathrm{E}$ ratios, as Portfolio 1 consisted of firms with the lowest $\mathrm{P} / \mathrm{E}$ and Portfolio 4 consisted of firms with the highest $\mathrm{P} / \mathrm{E}$. Portfolio 4 was eliminated due to some problems such as sudden dividend growth and being unprofitable. They concluded that the stocks with a low P/E ratio provided more returns than the stocks with a high $\mathrm{P} / \mathrm{E}$.

\subsection{Previous studies on PEG ratio}

Sun et al. (2006) conducted a research on the relationship between PEG ratio and stock returns over the period 1981-2000 and reported that there was a hump-shaped relationship between them. This 
means that the returns of portfolios that had a medium PEG ratio was more than the returns of portfolio with a low or high PEG ratio. This actually questioned the strategy of low PEG.

Chahin and Choudhry (2010) compared growth stocks and value stocks on 11 European countries over the period 1988-2002. The results indicated that value strategy had a better performance than growth strategy in European countries and value portfolios with a high growth rate and growth portfolios with a low growth rate have had, respectively, the best and the worst performance. In addition, the strategy based on the borrowing sale of stocks with a PEG more than 1 and purchase of stocks with PEG less than 1 has produced the highest returns.

\section{Research Hypothesis}

Since the method of the present study is deductive-descriptive, the objective is to answer the research questions. The following hypotheses are expressed, descriptively.

1. PEG ratio has an impact on stock returns of firms accepted in Tehran Stock Exchange.

2. P/E ratio has an impact on stock returns of firms accepted in Tehran Stock Exchange.

3. PEG ratio has a greater impact than $\mathrm{P} / \mathrm{E}$ ratio on stock returns of firms accepted in Tehran Stock Exchange.

Statistical population of research included the firms accepted in Tehran Stock Exchange (TSE). The author obtained data from Tadbir Pardaz and Rahavarde Novin Database which has been published as an annual report and formally approved by the Audit Organization or the Association of Official Accountants. The firms accepted in TSE, regardless of their geographical location and considering the following criteria, were selected as the available or limited non-random statistical sample.

1- Their shares are traded on the Stock Exchange.

2- Their fiscal year finishes on 29/12.

3- They are not an investment firm.

Required data were collected by the study of literature related to the research topic, exploring the internet, and the study of documents. Data were described using central indices including mean, median, standard deviation, variance of changes range, minimum, and maximum. After initial classification and processing of data, regression and Pearson Correlation Coefficient were used to answer the question. The firms accepted on TSE were divided into 9 groups shown on Table 1 and Table 2 based on their dividend growth rate and ratios of $\mathrm{P} / \mathrm{E}$ and $\mathrm{PEG}$, respectively. Then, the return of each group was calculated and compared with each other.

Table 1

Corporations Grouping

\begin{tabular}{|c|c|c|c|c|}
\hline & \multicolumn{4}{|c|}{ Growth rate } \\
\hline \multirow{4}{*}{$\begin{array}{l}\mathrm{R} / \mathrm{E} \\
\text { ratio }\end{array}$} & Low & Medium & High & General state \\
\hline & Pure value & The worth more than the price & The worth much more than the price & Value \\
\hline & The price more than the worth & Normal & The worth more than the price & Normal \\
\hline & The price much more than the worth & The price more than the worth & Pure growth & Growth \\
\hline
\end{tabular}

Table 2

PEG ratio and dividend growth rate

\begin{tabular}{|c|c|c|c|c|c|}
\hline & & \multicolumn{4}{|c|}{ Growth rate } \\
\hline \multirow{4}{*}{$\begin{array}{l}\text { PEG } \\
\text { ratio }\end{array}$} & & Low & Medium & High & General state \\
\hline & Low & Pure value & $P E G \cong 1$ & $\mathrm{PEG}<1$ & Value \\
\hline & Medium & $P E G \cong 1$ & Normal & $P E G \cong 1$ & Normal \\
\hline & High & $\mathrm{PEG}>1$ & $P E G \cong 1$ & Pure growth & Growth \\
\hline
\end{tabular}


Generally, $\mathrm{P} / \mathrm{E}$ ratio, $\mathrm{PEG}$ ratio, dividend growth rate are independent variables and stock returns is the dependent variable. Price here means the last market price (transaction) per share at the end of fiscal year, which is declared by TSE officials. Earnings per share (EPS) of each firm is calculated through dividing the preferred stock dividends by the number of ordinary shares in the hands of shareholders, after subtraction of the tax. Among three types of EPS including realized EPS, current EPS, and expected EPS, realized EPS was used in the present study and P/E ratio was calculated as follows:

\section{$\frac{P}{E}=\frac{\text { Stock Price }}{\text { Earning Per share (EPS) }}$}

Dividend growth rate was determined by the following equation and based on the realized EPS:

$\bar{G}=\left(\frac{E \hat{P} S_{N}}{E \hat{P} S_{0}}\right)-1$

And PEG ratio was calculated by the following formula:

PEG Ratio $=\frac{\frac{\text { Price }}{\text { Earning per share }}}{\text { Rate of Growth Ea ming }}$

Investment returns in stocks in a certain period is determined with regard to the price of the first and the end of period and benefits acquired from ownership. Benefits of ownership are belong to shareholders in periods that general assembly is held, otherwise benefits of stock ownership is considered equal to zero. Efficiency including the input $=[($ Day Price - Base Price $)+$ Bonus shares + Priority $+($ DPS $) /($ Base Price $)+(1000 \times$ Percent of the capital increase from input $)] \times 100$

\section{Research findings}

Firstly, primary variables were described using some statistical parameters such as mean, standard deviation, and charts and then the relationship between variables and their effects on each other were studied based on the performed analysis.

\subsection{The effect of variables on returns}

The first research question is as follows: How are the effects of the ratios of PEG and P/E on stock returns of the firms accepted in TSE? This question has two parts; one part is related to the effect of $\mathrm{P} / \mathrm{E}$ ratio on returns and another one deals with the effect of $\mathrm{PEG}$ ratio on returns. In order to examine the effect of $\mathrm{P} / \mathrm{E}$ ratio on stock returns, Pearson Correlation Coefficient was used and the results are shown in Table 3.

\section{Table 3}

Correlation Coefficient between $\mathrm{P} / \mathrm{E}$ ratio and stock returns

\begin{tabular}{ll} 
Simultaneous entry of variables method & Method = inter \\
Correlation Coefficient & 0.114 \\
Coefficient of determination & 0.013 \\
\hline
\end{tabular}

In order to determine the relationship between $\mathrm{P} / \mathrm{E}$ and stock returns, the simple linear regression was estimated that its results are shown in Table 4. 
Table 4

Estimation of the simple linear regression between $\mathrm{P} / \mathrm{E}$ and stock returns

\begin{tabular}{llll}
\hline Model & $\mathrm{B}$ & $\mathrm{SE}$ & Beta \\
\hline Constant figure & 12.565 & 2.462 & 0.114 \\
P/E ratio & 0.485 & 0.147 & \\
Mean square of regression & 43801587 & & \\
Mean square of the remaining & 3340635.279 & & \\
\hline
\end{tabular}

Based on this estimation, regression line equation is equal to $\bar{y}=12.565+0.114 \mathrm{x}_{1}$. The results of the regression test between $\mathrm{P} / \mathrm{E}$ ratio and average stock returns of the firms accepted in TSE implies that on unit change in $\mathrm{P} / \mathrm{E}$ ratio, on average, causes 0.114 unit change (Percentage is the unit of change) in average stock returns. Coefficient of determination which is 0.013 shows that variability of returns for 0.013 unit depends on $\mathrm{P} / \mathrm{E}$ ratio and the rest of it depends on other factors. Based on variable coefficient in estimation equation, it can be said that this a direct correlation but it is investigated poor because coefficient of determination approaches to zero.

The second question investigates how PEG ratio influences on stock returns of the TSE firms. Like the previous question, Pearson Correlation Coefficient was used to examine the effect of PEG ratio on stock returns and the results are shown in Table 5.

\section{Table 5}

Correlation Coefficient between PEG ratio and stock returns

Simultaneous entry of variables method

Correlation Coefficient Method=inter

Coefficient of determination 0.019 0.00036

Based on correlation evaluation, it was found that there was a direct relationship between PEG ratio and stock return, but it is a very poor correlation because estimation coefficient approaches to zero. Then, in order to determine the relationship between PEG and stock returns, the simple linear regression was estimated that its results are shown in Table 6.

\section{Table 6}

Estimation of the simple linear regression between PEG and stock returns

\begin{tabular}{llll}
\hline Model & B & SE & Beta \\
\hline Constant figure & 16.212 & 2.228 & -0.019 \\
PEG ratio & -0.001 & 0.002 & \\
Mean square of regression & 1165408 & & \\
Mean square of the remaining & 338327.728 & & \\
\hline
\end{tabular}

Based on the results, estimating equation is expressed as $\bar{y}=16.212-0.019 \mathrm{x}_{1}$. The results of the regression test between PEG ratio and average stock returns of the firms accepted on TSE indicate that one unit change in PEG ratio, on average, causes - 0.019 unit change (Percentage is the unit of change) in average stock returns. Coefficient of determination which is equal to 0.00036 shows that variability of returns for 0.00036 unit depends on PEG ratio and the rest of it depends on other factors. Considering the negative coefficient of $x$ in the equation, there is an inverse relationship between variables but it is very poor because coefficient of determination approaches to zero. The next question is to investigate the effects of PEG ratio and P/E ratio on stock returns of TSE firms. Table 7 provides a summary of this comparison.

Table 7

Comparison of the effects of PEG ratio and P/E ratio on stock returns of the firms accepted in Tehran Stock Exchange 


\begin{tabular}{llll}
\hline Model & B & Beta & SE \\
\hline PEG ratio & -0.001 & -0.019 & 0.002 \\
P/E ratio & 0.485 & 0.114 & 0.147 \\
\hline
\end{tabular}

As the results of research also show, PEG ratio has less impact on stock returns than $\mathrm{P} / \mathrm{E}$ ratio does. On the other hand, there is an inverse relationship between PEG ratio and stock returns, while the relationship between $\mathrm{P} / \mathrm{E}$ and stock returns is direct. If PEG ratio increases by one unit, stock returns decreases by -0.019 , on average, while if $\mathrm{P} / \mathrm{E}$ ratio increases by one unit, stock returns increases by 0.114 . Additionally, stock returns is affected by $\mathrm{P} / \mathrm{E}$ ratio more than $\mathrm{PEG}$ ratio.

\subsection{Ranking of firms}

In this part of the study, the firms accepted in Tehran Stock Exchange were divided into 9 groups based on their dividend growth rate and ratios of P/E and PEG using the model of Chahin and Choudhry (2010). Then. the returns of each group was calculated and compared with other groups.

\section{Table 8}

Ranking matrix based on the dividend growth rate

\begin{tabular}{|c|c|c|c|c|}
\hline & \multicolumn{4}{|c|}{ Growth rate } \\
\hline \multirow{4}{*}{$\begin{array}{l}\mathrm{R} / \mathrm{E} \\
\text { ratio }\end{array}$} & Low & Medium & High & General state \\
\hline & Pure value & The worth more than the price & The worth much more than the price & Value \\
\hline & The price more than the worth & Normal & The worth more than the price & Normal \\
\hline & The price much more than the worth & The price more than the worth & Pure growth & Growth \\
\hline
\end{tabular}

According to Table 8, matrices are formed for each year.

Table 9

Ranking matrix of firms from 2004 to 2009 based P/E and PEG ratios

\begin{tabular}{|c|c|c|c|c|c|c|c|c|c|}
\hline \multirow[b]{2}{*}{ Year } & \multirow[b]{2}{*}{ Coefficient } & \multicolumn{2}{|l|}{ Low } & \multicolumn{2}{|l|}{ Medium } & \multicolumn{2}{|l|}{ High } & \multicolumn{2}{|c|}{ General state } \\
\hline & & $\begin{array}{l}\text { Medium } \\
\mathrm{P} / \mathrm{E}\end{array}$ & $\begin{array}{l}\text { Medium } \\
\text { PEG }\end{array}$ & $\begin{array}{l}\text { Medium } \\
\mathrm{P} / \mathrm{E}\end{array}$ & $\begin{array}{l}\text { Medium } \\
\text { PEG }\end{array}$ & $\begin{array}{l}\text { Medium } \\
\mathrm{P} / \mathrm{E}\end{array}$ & $\begin{array}{l}\text { Medium } \\
\text { PEG }\end{array}$ & $\begin{array}{l}\text { Medium } \\
\mathrm{P} / \mathrm{E}\end{array}$ & $\begin{array}{l}\text { Medium } \\
\text { PEG }\end{array}$ \\
\hline \multirow{3}{*}{2004} & Low & 33.06 & 26.65 & 8.95 & 6.12 & 62.35 & 36.45 & Value & Value \\
\hline & Medium & 0.17 & 11.66 & 10.27 & 28.19 & 66.69 & 49.43 & Normal & Normal \\
\hline & High & 17.86 & 34.25 & 61.58 & 35.25 & 35.03 & 79.58 & Growth & Growth \\
\hline \multirow{3}{*}{2005} & Low & -17.26 & -13.08 & -15.19 & -14.22 & -1.54 & -6.91 & Value & Value \\
\hline & Medium & -22.98 & -21.18 & -14.82 & -20.37 & -11.78 & -1.4286 & Normal & Normal \\
\hline & High & -16.29 & 8.19 & -7.93 & -6.6 & 2.48 & 0.36 & Growth & Growth \\
\hline \multirow{3}{*}{2006} & Low & -5.57 & 38.08 & -6.91 & 18.65 & 37.69 & 36.45 & Value & Value \\
\hline & Medium & 14.71 & 2.67 & 19.21 & -22.83 & 62.65 & 59.33 & Normal & Normal \\
\hline & High & 20.21 & -4.15 & 18.53 & 15.43 & 14.24 & 26.19 & growth & Growth \\
\hline \multirow{3}{*}{2007} & Low & -12.58 & 1.14 & -3.51 & -9.89 & 24.27 & 52.16 & Value & Value \\
\hline & Medium & -20.34 & -6.19 & -5.87 & -12.07 & 15.27 & 43.07 & Normal & Normal \\
\hline & High & 15.01 & -85.18 & 6.56 & 7.63 & 63.25 & 26.07 & Growth & Growth \\
\hline \multirow{3}{*}{2008} & Low & -27.02 & -6.42 & -3.15 & -4.59 & 21.96 & 35.21 & Value & Value \\
\hline & Medium & 4.88 & -20.76 & -1.87 & 2.71 & 7.097 & 14.23 & Normal & Normal \\
\hline & High & -19.33 & -14.72 & 2.87 & 4.18 & 11.26 & 11.4 & growth & Growth \\
\hline \multirow{3}{*}{2009} & Low & 41.24 & 16.51 & 57.23 & 19.36 & 2 & 31.13 & Value & Value \\
\hline & Medium & 35.21 & 61.66 & 25.77 & 29.68 & 60.5 & 61.18 & Normal & Normal \\
\hline & High & 56.53 & 99.84 & 32.5 & 48.18 & 156.44 & 124.98 & growth & Growth \\
\hline
\end{tabular}

Evaluation of growth and overall ranking of these firms over five studied years based on P/E and PEG have been summarized in Table 10 and Table 11. 
Table 10

Overall ranking of firms based on $\mathrm{P} / \mathrm{E}$ ratio during 5 years

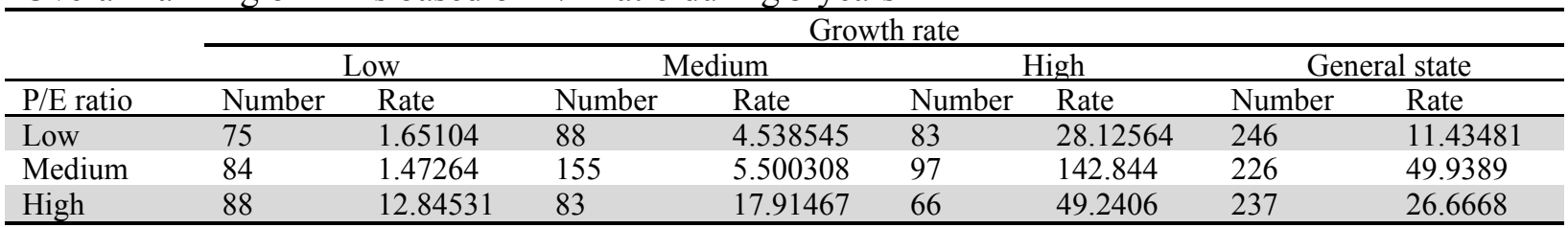

Table 11

Overall ranking of firms based on PEG ratio during 5 years

\begin{tabular}{|c|c|c|c|c|c|c|c|c|}
\hline \multirow{3}{*}{ PEG ratio } & \multicolumn{8}{|c|}{ Growth rate } \\
\hline & \multicolumn{2}{|c|}{ Low } & \multicolumn{2}{|c|}{ Medium } & \multicolumn{2}{|c|}{ High } & \multicolumn{2}{|c|}{ General state } \\
\hline & Number & Rate & Number & Rate & Number & Rate & Number & Rate \\
\hline Low & 72 & 12.16188 & 172 & 1.824911 & 1 & 31.13 & 1 & 15.3893 \\
\hline Medium & 169 & 1.65479 & 29 & - & 138 & 41.28783 & 138 & 10.27431 \\
\hline High & 6 & 15.54167 & 145 & 21.07326 & 86 & 35.13556 & 86 & 23.91683 \\
\hline
\end{tabular}

According to the above tables, a general picture of pure value stock and pure growth stock considering the ratios of $\mathrm{P} / \mathrm{E}$ and PEG can be depicted and research strategies can be planned and developed using these data and results.

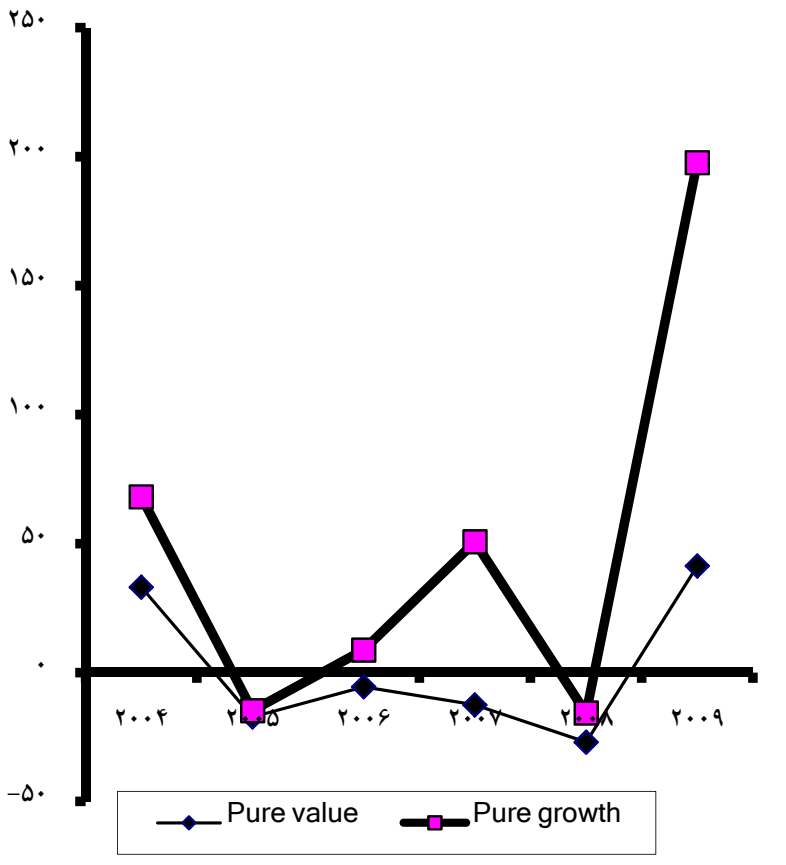

$\mathrm{P} / \mathrm{E}$ ratio from 2004 to 2009

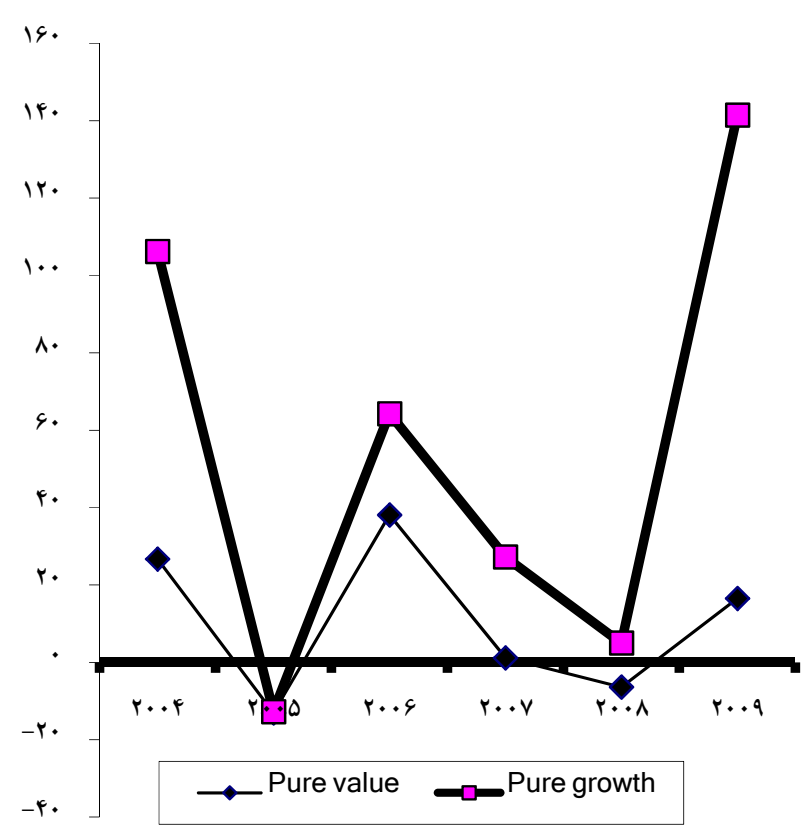

PEG ratio from 2004 to 2009

Fig. 1. Variation in returns of pure value stock and pure growth stock

\section{Conclusion}

The relationship between $\mathrm{P} / \mathrm{E}$ ratio and stock returns of the firms accepted in Tehran Stock Exchange was tested using regression and Pearson Correlation Coefficient. $\beta$ coefficient and jorrelation coefficient were obtained +0.114 and coefficient of determination was calculated 0.013 . This means that one unit change in $\mathrm{P} / \mathrm{E}$ ratio, on average, causes 0.114 unit change in stock returns of firms accepted in Tehran Stock Exchange and coefficient of determination (0.013) shows that variability of 
returns for 0.013 unit depends on $\mathrm{P} / \mathrm{E}$ ratio. According to the sign of $\beta$ coefficient, there is a direct relationship between $\mathrm{P} / \mathrm{E}$ ratio and stock returns. In addition, the relationship between PEG ratio and stock returns of the firms accepted in Tehran Stock Exchange was tested using regression and Pearson Correlation Coefficient. $\beta$ coefficient, Correlation coefficient, and coefficient of determination were obtained $-0.019,0.019$, and 0.00036 , respectively. This means that one unit change in PEG ratio, on average, causes 0.019 unit change in stock returns of firms accepted in Tehran Stock Exchange and coefficient of determination (0.00036) shows that variability of returns for 0.00036 unit depends on PEG ratio. According to the sign of $\beta$ coefficient, there is a inverse relationship between PEG ratio and stock returns.

The present study also showed that the coefficient of determination of $\mathrm{P} / \mathrm{E}$ ratio was much more than that of PEG ratio. This means that returns was changed more by $\mathrm{P} / \mathrm{E}$ ratio than $\mathrm{PEG}$ ratio and thereby, stock returns of studied firms was more affected by $\mathrm{P} / \mathrm{E}$ ratio than $\mathrm{PEG}$ ratio. According to the sign of $\beta$ coefficient, the relationship between of $\mathrm{P} / \mathrm{E}$ ratio with stock returns was direct, while there was an inverse relationship between PEG ratio and stock returns.

According to the matrix of Chahin and Choudhry (2010) Model, four strategies can be proposed for each matrix.

The following strategies are expressed according to the tables of $\mathrm{P} / \mathrm{E}$ ratio and dividend growth rate:

- Selling the pure value stock and buying the pure growth stock

- Selling the all value stock and buying the all growth stock

- Selling the pure growth stock and buying the pure value stock

- selling the all growth stock and buying the all value stock

Returns of above-mentioned strategies is $47.58956,15.23319,47.58956$, and -15.23199 , respectively.

According to the results, it can be concluded that the first strategy was better than the second one, the second strategy was better than the fourth one, and the fourth strategy was better than the third one.

The following strategies are expressed according to the tables of $\mathrm{P} / \mathrm{E}$ ratio and dividend growth rate:

- Selling the pure value stock and buying the pure growth stock

- Selling the all value stock and buying the all growth stock

- Selling the pure growth stock and buying the pure value stock

- selling the all growth stock and buying the all value stock

Returns of above-mentioned strategies were $22.97368,8.8779,22.97368$, and -8.8779 , respectively. According to the results, it can be concluded that the first strategy was better than the second one, the second strategy was better than the fourth one, and the fourth strategy was better than the third one.

It should be noted that all these conclusions are presented by considering the current situation of financial market in Iran and are true when other factors are constant and different results may be obtained in different conditions. Additionally, these results are related to statistical population of the present study and don't include all firms.

\section{References}

Akbari, F. (2012). Financial statement analysis. Accounting \& Auditing Researchers, 129. 
Basu, S. (1977). Investment performance of common stocks in relation to their price-earnings ratios: A test of the efficient market hypothesis. The Journal of Finance, 32(3), 663-682.

Chahin, S., \& Choudhry, T. (2010). Price to earnings, growth radio and value growth based strategies. Social Science Research Network, 19(4).

Easton, P. D. (2004). PE ratios, PEG ratios, and estimating the implied expected rate of return on equity capital. The accounting review, 79(1), 73-95.

Fama, E. F., \& French, K. R. (1993). Common risk factors in the returns on stocks and bonds. Journal of financial economics, 33(1), 3-56.

Goodman, D. A., \& Peavy III, J. W. (1985). The risk universal nature of the P/E effect. The Journal of Portfolio Management, 11(4), 14-16.

Godarzi, A. (2007). The relationship between financial ratios with share's return. Tehran University, Management Department, Un-published dissertation.

Jahankhani, A., \& Parsaian, A. (1997). Investment management \& Issues Evaluation. Management \& Economy of Tehran, $1^{\text {th }}$ ed.

Jones, C. P. (2007). Investments: analysis and management. John Wiley \& Sons.

Miraiee, H. (2007). The relation between increase in capital and Iranian firms' Returns. Shahid Beheshti University, un-published dissertation

Namazi, M. (2006). The relationship between financial ratios with firms' return. Accounting \& Auditing Reviews, 44.

Noravesh, I., \& Dianati Deilami, Z. (2004). Financial Management. Tehran University, $2^{\text {nd }}$ ed.

Niko Maram, H., Rahnama Rod Poshti, F., \& Heybati, F. (2006). The Principles of Financial Management, Termeh Publisher.

Raie, R., \& Telengi, A. (2004). Advanced Investment Management, Sanat Publisher.

Sun, C., Sze, R., \& Zhang, M. (2006). Folic acid-PEG conjugated superparamagnetic nanoparticles for targeted cellular uptake and detection by MRI. Journal of Biomedical Materials Research Part A, 78(3), 550-557. 